\title{
EDITORIAL
}

\section{Obituary: a tribute to Yoshihiro Kaneko, MD}

\author{
Hypertension Research (2016) 39, 565-566; doi:10.1038/hr.2016.59
}

$\mathrm{D}_{\mathrm{s}}$ Yoshihiro Kaneko passed away in February of 2016. He had a central role in the founding of the Japanese Society of Hypertension (JSH) and was the president of the first JSH scientific meeting. 'A great star has fallen' with the death of the person driving research on hypertension in our country.

Dr Kaneko graduated from Tokyo University. He worked in the nephrology-hypertensive group led by Professor Kenzou Oshima in the Department of Internal Medicine II, Tokyo University. By collecting venous blood from a hypertension patient and injecting it into a rabbit, he determined that some patients with renal dysfunction show elevated blood pressure. This was $>10$ years before the bioassay method was successfully developed.

He then went to the Cleveland clinic, the Mecca for the study of hypertension, from 1958 through 1963 and studied the 'Hypertension and renin-angiotensin system' under Dr Page and Dr McCabbin. During this time, he returned home temporarily and married his present wife. After returning to Japan, he developed a bioassay method of plasma renin activity (PRA) that used the injection of plasma into a rabbit. Circa 1965, he succeeded in measuring renin release from renal vein samples, and also proved that renin release from the kidney is dependent upon decreased perfusion pressure, but not decreased renal blood flow. He suggested the mechanism of blood pressure elevation in the renovascular hypertension. ${ }^{1}$

This report was highly valued throughout the world, and Dr Lee of England introduced this thesis by saying 'An important series of observations has recently been made by Kaneko et al.' ${ }^{1}$ in his book 'Renin and Hypertension', 2 where he also stated that 'these important findings demonstrate that the threshold of arterial pressure for renin release in renovascular hypertension is shifted to arrange much higher than in the normal. I consider this paper a fundamental contribution to the thesis that in renovascular hypertension renin release may be inappropriate. The importance of this Japanese work cannot be overemphasized.' Moreover, the renowned Dr Goldblatt wrote in his thesis $^{3}$ (1972) that the team of Dr Kaneko was the first in the world to measure renin release from the kidney in man. Dr Kaneko reported in 1970 that ganglion-blocking agents significantly reduced renin release from the kidney in hypertensive patients. ${ }^{4} \mathrm{He}$ also investigated the influence of the then permitted $\beta$-blocker and propranolol, and found that it reduced renin release from the kidneys and decreased PRA in hypertensive patients.

Looking back upon this period in his life, he said, 'I feel very fortunate, satisfied and thankful to be able to be engaged in the work at the forefront of the world for some time. I'd like to sincerely appreciate cooperative researchers.'

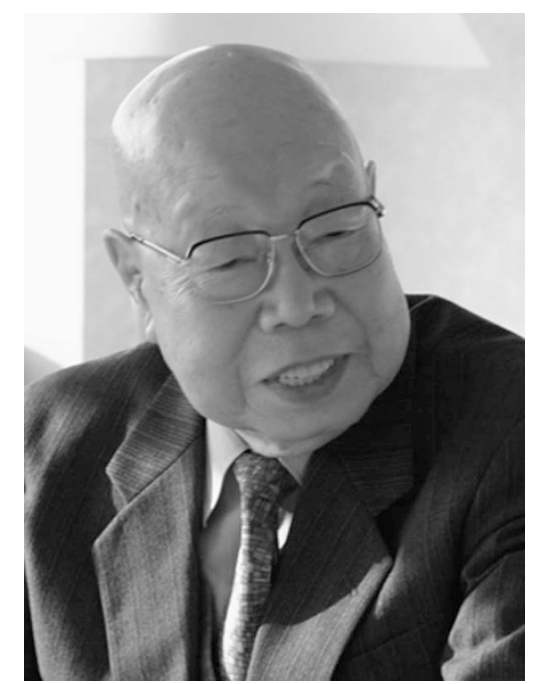

Dr Kaneko was appointed as a Professor in the Department of Internal Medicine II, Yokohama City University. Later, he founded the JSH with 10 supporters, including Professor Teruo Omae and others, with the aim of promoting the study of hypertension, and attempting to encourage progress in the diagnosis, prevention and treatment of this disease. Before that, the study of hypertension had been expressed at many different and related societies.

The first JSH Scientific Meeting was held in Yokohama. Dr Kaneko's teacher, Dr James W McCubbin of Cleveland, was invited to give the lecture and it was titled 'A Personal View of the Role of the Sympathetic Nervous System in Hypertension.' Dr McCubbin spoke about the relationship between the autonomic nervous system, the control of blood volume and 'reset theory', which greatly impressed the audience.

The scientific meeting of the JSH was founded by the Kaneko group with the idea to take enough time to present high-quality studies in one place; however, with the increase in members, a number of studies have been presented in more than one place. Because of the tendency of today's time, it is necessary, but Professor Kaneko was often said to deplore the decline in the quality of the society. I think many researchers were frightened by the severe questions posited by Professor Kaneko at the meeting. Examples of such questions include 'what is new in your study, what is the clinical significance' and so on, which are very strict and fundamental. In contrast, on social occasions, we had free and delightful talk, and 
keenly felt his affection and passion about the study of hypertension and the JSH.

Soon after his promotion to Professor of Yokohama City University, he stated at a medical staff meeting his aspiration for the Department of Internal Medicine II office to have many international students and veteran professionals, with $>10$ years of experience, and he implemented a spirit of 'Striking while the iron is hot.' He said in the 50th anniversary journal of the Department of Internal Medicine II, 'I think I was completely engrossed in acting as I wished,' and 'The Department produced nine professors those days. I am deeply moved when I think of those fourteen years they were a very happy time for me,' 'The Department of Internal Medicine II, as far as it is filled with excellent members and teachers who are always pleasant to support, can develop even further.'

Please accept my deepest sympathy for his death, I pray that his soul may rest in peace.
Satoshi Umemura

Yokohama City University, Department of Medical Science and Cardiorenal Medicine, Yokohama, Japan E-mail: umemuras@yokohama-cu.ac.jp

1 Kaneko $\mathrm{Y}$, Ikeda $\mathrm{T}$, Takeda $\mathrm{T}$, Ueda $\mathrm{H}$. Renin release during acute reduction of arterial pressure in normotensive subjects and patients with renovascular hypertension. J Clin Invest 1967; 46: 705-716.

2 Lee MR. Renin and Hypertension. Lloyd-Luke: London: 1969; 160-163.

3 Goldblatt H, Haas E, Haas R. Studies on renin: II. Continuous infusion of homologous renin at very low rates in intact or nephrectomized, conscious or anesthetized dog. Circ Res 1972; 31: 74-82.

4 Kaneko Y, Takeda T, Ikeda T, Tagawa H, Ishii M, Takabatake Y, Ueda H. Effect of ganglion-blocking agents on renin release in hypertensive patients. Circ Res 1970; 27: 97-103. 